\title{
Dentofacial Characteristics among Monozygotic and Dizygotic Twin Pairs from a Unique Village of Twins in South India: A Descriptive Cross-sectional Study
}

\author{
${ }^{1}$ Praveen S Jodalli, ${ }^{2}$ Ganesh Shenoy Panchmal, ${ }^{3}$ Vinej Somaraj, ${ }^{4}$ Shafees Koya
}

\section{ABSTRACT}

Aim: To assess the dentofacial characteristics of a mystery village of twins in South India.

Materials and methods: A descriptive cross-sectional study was carried out among of 22 twin pairs (10 monozygotic twins and 12 dizygotic twins). The evaluation was done in terms of height, weight, dentofacial profile, and occlusion status based on anthropometric, photographic, and dental cast analysis.

Results: Data obtained upon analysis of anthropometric measurements, photographic data, and dental cast evaluation revealed a set of characteristics peculiar to the twins of this unique village.

Conclusion: Twin studies are a fascinating method of research because of their ability to correctly isolate a characteristic and determine its impact, especially in terms of dentofacial characteristics.

Clinical significance: Twin research design involving the comparison of variables among monozygotic (identical) and dizygotic (fraternal) twins is a method by which researchers quantify and classify the contribution of genes and other extraneous factors influencing heredity on the dentofacial complex and dentition.

Keywords: Dizygotic twins, Genetics, Kodinhi, Monozygotic twins, Twin study.

How to cite this article: Jodalli PS, Panchmal GS, Somaraj V, Koya S. Dentofacial Characteristics among Monozygotic and Dizygotic Twin Pairs from a Unique Village of Twins in South India: A Descriptive Cross-sectional Study. Int J Recent Surg Med Sci 2017;3(1):25-28.

Source of support: Grants from Yenepoya University, Mangaluru, Karnataka, India

Conflict of interest: None

\footnotetext{
${ }^{1}$ Reader, ${ }^{2}$ Senior Professor and Head, ${ }^{3,4}$ Senior Lecturer

${ }^{1,2}$ Department of Public Health Dentistry, Yenepoya Dental College, Mangaluru, Karnataka, India

${ }^{3}$ Department of Public Health Dentistry, Rajas Dental College \& Hospital, Tirunelveli, Tamil Nadu, India

${ }^{4}$ Department of Orthodontics, Yenepoya Dental College Mangaluru, Karnataka, India

Corresponding Author: Vinej Somaraj, Senior Lecturer Department of Public Health Dentistry, Rajas Dental College \& Hospital, Tirunelveli, Tamil Nadu, India, Phone: +918105170815 e-mail:v2vinej@gmail.com
}

\section{INTRODUCTION}

Research with twins provides valuable insight into the genetic and environmental contributing factors responsible for the variations in both physical and behavioral traits and disorders. Although it is difficult to predict the exact influence of heredity due to various genetic patterns, twin studies are instrumental in offering evidence against the purely environmental model. ${ }^{1,2}$

Monozygotic, or "identical," twins share nearly 100\% of their genetic polymorphisms, whereas dizygotic, or "fraternal," twins share only about $50 \%$. This means that most variation in a monozygotic pair trait is due to their unique experiences, while in the case of dizygotic twins, there might be the influences of extraneous factors. ${ }^{3}$ Studies with monozygotic and dizygotic twins are helpful because they tend to share many aspects of their environment by virtue of being born at the same time and place.

The present study results are based on the assessment done among the members of twins of Kodinhi village, Kerala, South India, in terms of their height, weight, dentofacial profile, and occlusion status.

\section{MATERIALS AND METHODS}

A descriptive cross-sectional study was conducted among 22 twin pairs aged 13 to 25 years born in Kodinhi village, Kerala, India. Kodinhi $\left(11.0410^{\circ} \mathrm{N}, 76.0830^{\circ} \mathrm{E}\right)$ a village in Malappuram District, Kerala, South India, which is home to 2,000 to 2,500 villagers, took the scientific world by surprise when a survey by the locals concluded that there is an unusually larger number of twin births (approximately 250 twins pairs) and two sets of triplets. This mystery phenomenon of high rates of twin birth further puzzles as it has been observed that women who are married to the youth of this village and also those who are married off from this village gave birth to twins. The exact cause of this peculiar rate of twin birth in this particular village is a matter of research. The other villages that have reported a high rate of twinning are Igbo-Ora (Nigeria) and Cândido Godói (Brazil). ${ }^{4}$

The study protocol was approved by the University Ethics Committee. After obtaining consent and assent of the study participants and parents, the following 
parameters were recorded: Anthropometric measurements: Height (in $\mathrm{cm}$ ) and weight (in $\mathrm{kg}$ ); photographs (facial profile and intraoral) and study models of dentition for the cast analysis. Spot sterilization of the instruments was carried out by autoclave and chemical sterilization. The impressions of the maxillary and mandibular arches were recorded using alginate impression material and were poured immediately with dental stone to obtain the study models. Descriptive statistics was obtained from the collected data.

\section{RESULTS}

The study population consisted of 22 twin pairs (10 monozygotic pairs and 12 dizygotic pairs) aged 6 to 25 years $[$ males $=25(58.6 \%)$ and females $=19(43.2 \%)$ ] born in Kodinhi village, Kerala, South India.

\section{Anthropometric Analysis}

The average height (in $\mathrm{cm}$ ) measured among monozygotic twin pairs was $150.80 \pm 16.15$ and for dizygotic twin pairs was $151.17 \pm 8.63$. Average weight (in $\mathrm{kg}$ ) recorded for monozygotic twin pairs was $38.39 \pm 13.46$ and that for dizygotic twin pairs was $40.67 \pm 9.39$.

\section{Photographic Analysis}

Photographic analysis (facial profile and intraoral profile view) of the twins was analyzed for the assessment of status and anomalies related to facial form (lateral and frontal) and intraoral status, and the following results were obtained:

- The majority of the twins had straight profile (95.5\%) and only a few had a concave profile (4.5\%).

- None of the twin pairs had a convex facial profile.

- In one case of a monozygotic twin pair (Fig. 1), one member had a concave facial profile, while the sibling had straight profile (Fig. 2), but the dentition profile showed otherwise (Figs $3 \mathrm{~A}$ and B), i.e., both the members of the pair had the same dental profile.

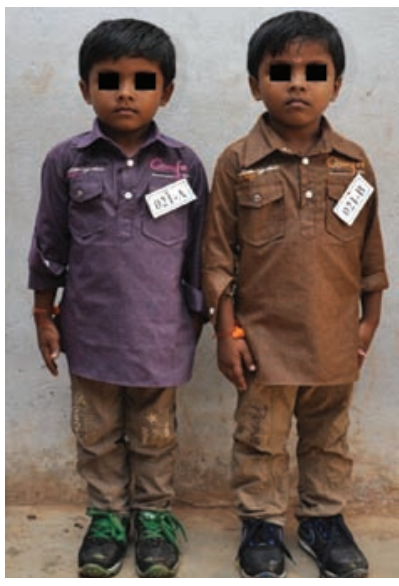

Fig. 1: Monozygotic twin pair
Table 1. Descriptive data of molar and canine relation

\begin{tabular}{llll}
\hline & \multicolumn{2}{l}{ Frequency } & Percent \\
\hline $\begin{array}{l}\text { Molar } \\
\text { relation }\end{array}$ & $\begin{array}{l}\text { Class I } \\
\text { Right side class I and left side }\end{array}$ & 2 & 90.9 \\
& $\begin{array}{l}\text { end-on } \\
\text { Right side class I and left side }\end{array}$ & 1 & 2.5 \\
& $\begin{array}{l}\text { missing } \\
\text { Right side class II and left side } \\
\text { class I }\end{array}$ & 1 & 2.3 \\
& $\begin{array}{l}\text { Total } \\
\text { Canine }\end{array}$ & 44 & 100.0 \\
Class I & 41 & 93.2 \\
$\begin{array}{l}\text { Right side class I and left side } \\
\text { class II }\end{array}$ & 1 & 2.3 \\
$\begin{array}{l}\text { Right side class I and left side } \\
\text { end-on }\end{array}$ & 1 & 2.3 \\
$\begin{array}{l}\text { Right side class II and left side } \\
\text { end-on }\end{array}$ & 1 & 2.3 \\
Total & 44 & 100.0 \\
\hline
\end{tabular}

\section{Model Analysis}

Analysis of the casts carried out to evaluate the dentition status and anomalies (type of malocclusion) revealed the following results:

- All the twins examined in the study had malocclusion.

- The severity of malocclusion differed among the twin pairs.

- The majority of the studied twins had class I malocclusion $(90.0 \%)$, end-on relation $(4.5 \%)$, and class II (4.6\%) and none had class III malocclusion (Table 1).

- Major type of malocclusion was crowding (43.33\%) followed by spacing (33.56\%), bidental/bimaxillary proclination $(7.88 \%)$, cross-bite $(11.33 \%)$, open-bite $(2.77 \%)$, and rotation $(1.13 \%)$.

- One monozygotic twin pair with cleft lip and palate (Fig. 4) had a different facial profile (Fig. 5) and contrasting dentition characteristics (Figs 6A and B ).

\section{Unique Cast Analysis}

The dental cast analysis revealed a set of unique findings among the twins of Kodinhi village, which are as follows:
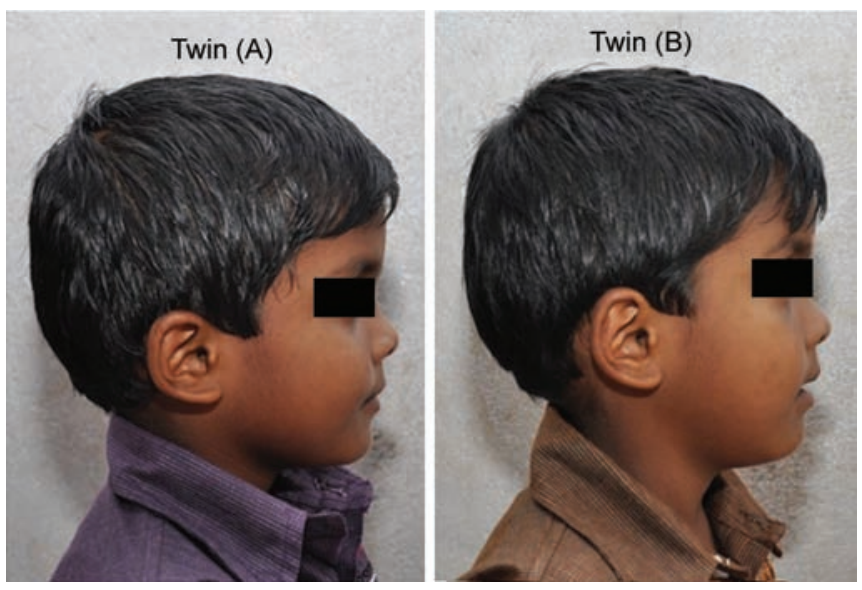

Fig. 2: Lateral profile view of the monozygotic twins 

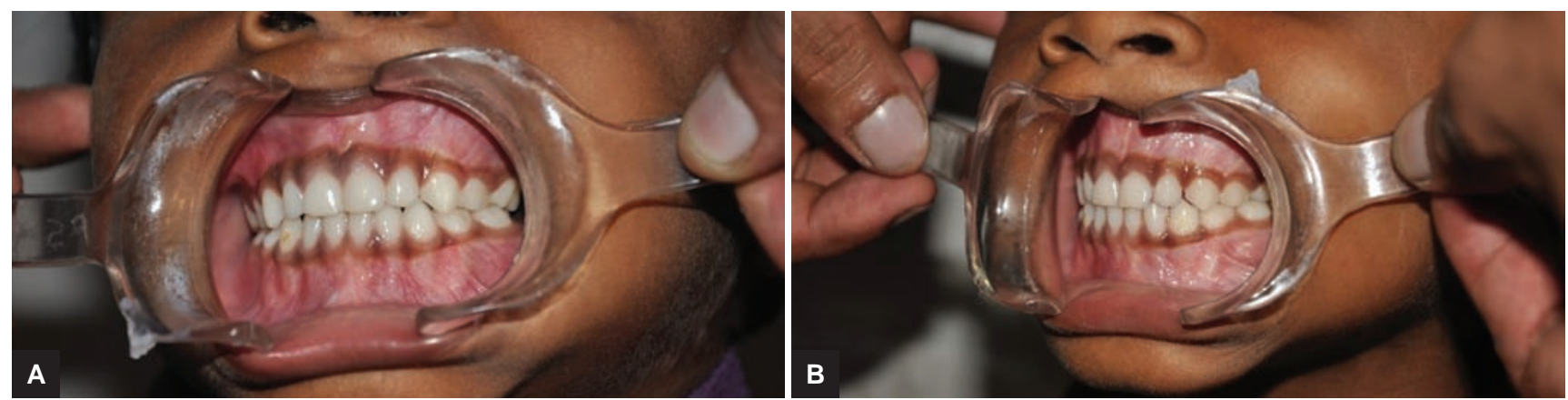

Figs $3 \mathrm{~A}$ and $\mathrm{B}$ : Lateral profile view of dentition among the monozygotic twins

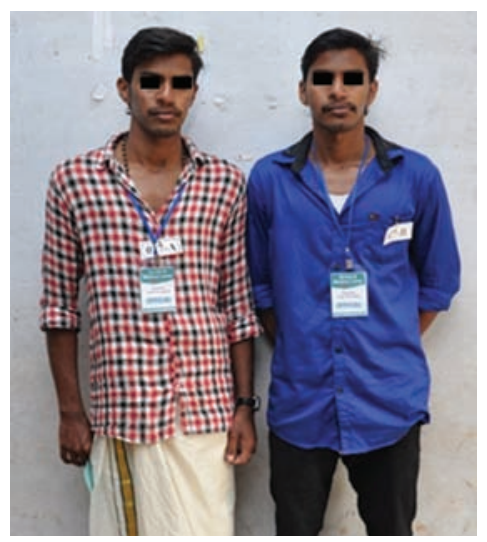

Fig. 4: Monozygotic twin pair with cleft lip and palate
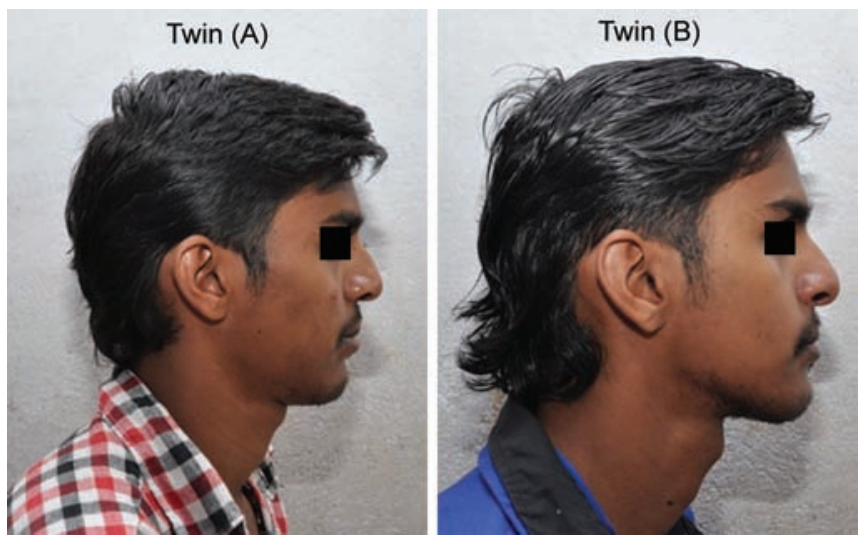

Fig. 5: Lateral profile view of monozygotic twin pair with cleft lip and palate
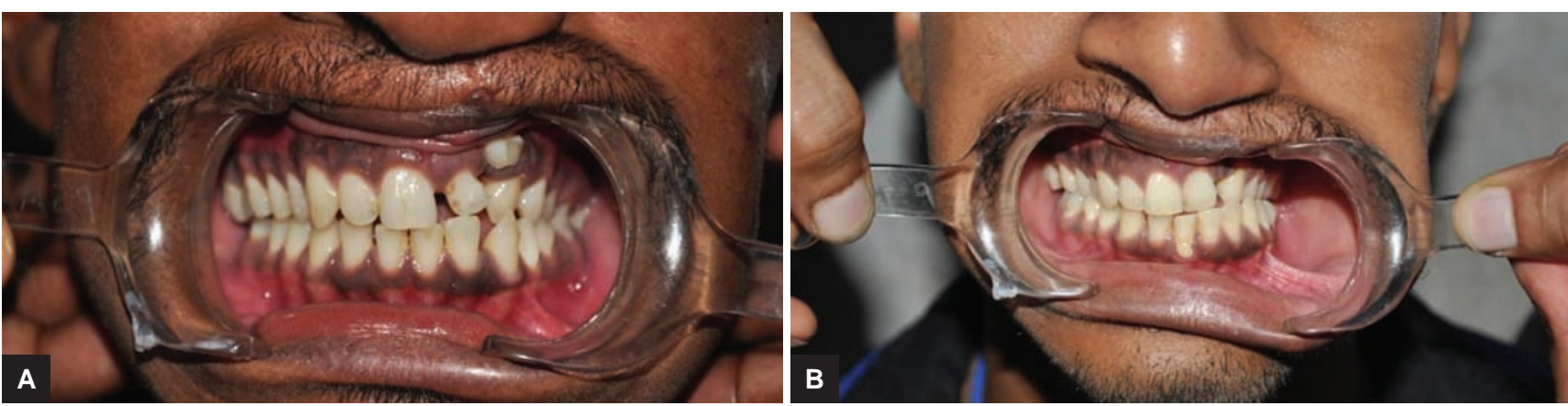

Figs 6 A and B: Facial profile view of dentition in monozygotic twin pair with cleft lip and palate

- Presence of fully erupted set of third molars in both the twins of a pair at the age of 15 in relation to both maxillary and mandibular arch.

- It was also found that there was a decreased number of bidental/bimaxillary proclination.

- Eruption sequence was faster among females.

- Eruption sequence differed among the twin pairs and when compared with growth it showed faster eruption for increasing height, especially among dizygotic twins.

\section{DISCUSSION}

Comparing monozygotic and dizygotic twins in their similarities and their differences gave some answers but raised some questions in relation to the genetic and environmental factors and mechanics influencing growth pattern. The facial characteristics displayed by the twins show the genetic control of inheritance, which also has been concluded by Weinberg et al. ${ }^{5}$

The genetic basis of development of skeletal structures is under the influence of environmental and genetic control, and importance of genetic control of malocclusion cannot be denied as evaluated by Cakan et al., ${ }^{6,7}$

As seen in the studied population, there is strong evidence that dental development is moderated by the same genetic mechanism that dictates maturation in general and sex maturational differences in particular. ${ }^{8,9}$ Other studies and reports carried out for various parameters on the same population reported in the literature too validates the above statement. ${ }^{10-12}$ 
The determination of body symmetry and clarification about the genetic factors that contribute to oral status, diseases, and disorders can be obtained from research involving twins. Multidisciplinary research involving dentists, geneticists, and twin researchers hold the promising future to unveil the mystery to unanswered questions of the past. ${ }^{13}$

\section{CONCLUSION}

The findings reported were based on the data obtained from the 22 twin pairs of the present study. It can be concluded that there are a set of unique dentofacial characteristics found among the twin population of Kodinhi village. The findings proved the fact that there is an association of time, size, and genetic control in case of the parameters used in the study. This study highlights the fact that twins provide an efficient and easy means of the study of the influence of heredity on dentofacial complex and dentition.

\section{ACKNOWLEDGMENT}

The authors acknowledge the twins and their family members for the participation in the study and are also grateful to the support from the Twins and Kins Association of Kodinhi for conducting the study.

\section{REFERENCES}

1. Lauweryns I, Carels C, Vlietinck R. The use of twins in dentofacial genetic research. Am J Orthod Dentofac Orthop 1993 Jan;103(1):33-38.
2. Nakata M. Twin studies in craniofacial genetics: a review. Acta Genet Med Gemellol (Roma) 1985;34(1-2):1-14.

3. Townsend G, Hughes T, Bockmann M, Smith R, Brook A. How studies of twins can inform our understanding of dental morphology. Front Oral Biol 2009;13:136-141.

4. Jodalli P, Panchmal GS, Sonde L, Somaraj V. Village of twins: A mystery. J Appl Dent Med Sci 2016 Apr-Jun;2(2):3-6.

5. Weinberg SM, Parsons TE, Marazita ML, Maher BS. Heritability of face shape in twins: a preliminary study using 3D stereophotogrammetry and geometric morphometrics. Dent 3000 2013;1(1):7-11.

6. Cakan DG, Ulkur F, Taner T (U ur). The genetic basis of facial skeletal characteristics and its relation with orthodontics. Eur J Dent 2012 Jul;6(3):340-345.

7. Cakan DG, Ulkur F, Taner T. The genetic basis of dental anomalies and its relation to orthodontics. Eur J Dent 2013 Sep; 7(Suppl 1):S143-S147.

8. Krogman WM. The role of genetic factors in the human face, jaws and teeth: a review. Eugen Rev 1967 Sep;59(3):165-192.

9. Cohen-Levy J, Kamoun-Goldrat AS, Simon Y, Lautrou A. Twins and the heritability of dentofacial phenotype. Orthod Fr 2007 Mar;78(1):69-77.

10. Jodalli P, Panchmal GS, Sonde L, Somaraj V. Comparative evaluation of posterior tooth dimensions among twin pairs from a unique village of twins: an ex-vivo study. Int J Appl Dent Sci 2016;2(4):12-15.

11. Jodalli P, Panchmal GS, Sonde L, Somaraj V. A non-identical twin from the village of twins with identical occlusal characteristics - a case report. Int J Health Sci Res 2016 Oct; 6(10): 260-264.

12. Jodalli PS, Panchmal GS, Sonde L, Somaraj V. Heterogeneous occlusal traits among monozygotic twins from the village of twins - a report of 3 cases. Ann Int Med Dent Res 2016;2(6): DE19-DE23.

13. Townsend G, Richards L, Hughes T, Pinkerton S, Schwerdt W. The value of twins in dental research. Aust Dent J 2003 Jun $1 ; 48(2): 82-88$. 